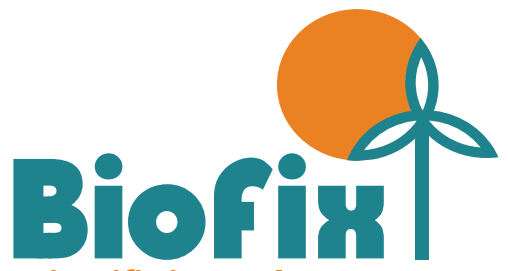

scientific journal

v. 2 n. 12017

\title{
MAPEAMENTO DAS ÁREAS PLANTADAS COM Eucalyptus spp. NO ESTADO DO PARANÁ
}

MAPPING Eucalyptus spp. PLANTATION AREAS IN PARANA STATE

Recebido em 15/03/2017

Aceito em 21/03/2017

Publicado em 20/04/2017

DOI: dx.doi.org/10.5380/biofix.v2i1.51222

\author{
Vinícius Morais Coutinho ${ }^{1}$ \\ Ana Paula Dalla Corte ${ }^{2}$ \\ Carlos Roberto Sanquetta ${ }^{3}$ \\ Ângela Maria Klein Hentz ${ }^{4}$ \\ Rozane Loyola Eisfeld ${ }^{5}$ \\ Flávio Augusto Ferreira do Nascimento ${ }^{6}$
}

\begin{abstract}
Universidade Federal do Paraná, Curitiba, Paraná, Brasil viniciusmorais@ufpr.br ${ }^{1}$,anapaulacorte@gmail.com ${ }^{2}$,carlos_sanquetta@hotmail.com ${ }^{3}$ \&angelakhentz@gmail.com ${ }^{4}$

Serviço Florestal Brasileiro, Curitiba, PR, Brasil. rozaneloyolaeisfeld@hotmail.com ${ }^{5}$
\end{abstract}

Secretaria da Agricultura e do Abastecimento do Paraná, Curitiba, PR, Brasil. flavionascimento@seab.pr.gov.br ${ }^{6}$

\section{RESUMO}

O objetivo deste trabalho foi mapear e quantificar as áreas com plantações de Eucalyptus spp. no estado do Paraná. Para tal, foram utilizados dados de áreas geoespacializadas de povoamentos florestais com classificação visual de imagens de satélite e validados com base em 988 pontos observados em campo. A área total plantada com Eucalyptus no estado totalizou 340.315 ha, o que representa $1,71 \%$ da superfície do estado. A região Centro-Sul possui $61,91 \%$ do total plantado com Eucalyptus no estado, a qual concentra a maior parte do parque industrial florestal. Vinte e cinco municípios do estado possuem mais da metade da área plantada com Eucalyptus, esses municípios encontram-se na região Centro-Sul, com destaque para o núcleo de Ponta Grossa, com mais de $42,27 \%$ da área plantada no estado, seguido pelos núcleos de Curitiba, Guarapuava, União da Vitória, Irati, Laranjeiras do Sul e Pato Branco. O Paraná é o estado com a quinta maior área plantada com Eucalyptus, em que o município de Telêmaco Borba, núcleo regional de Ponta Grossa, possui a maior área plantada no estado, com cerca de 45 mil hectares.

PALAVRAS-CHAVE: Classificação, Geoespacializados, Povoamentos florestais.

\section{ABSTRACT}

The aim of this study was to map and quantify Eucalyptus spp plantations areas in Parana State. For this, we used spatial area distribution data of forest stands and visual classification of satellite imagery, in which the data were validated by 988 points collected in the field. The total Eucalyptus area in the State totalized 340,315 ha, representing $1.71 \%$ of surface. The SouthCentral region has $61.91 \%$ of the total eucalyptus area in the State, which concentrates most of the forest industrial park. Twenty-five counties have more than half of the Eucalyptus plantation areas, of which are situated in the South-Central region, highlighting Ponta Grossa nucleus, with more than $42.27 \%$ of the plantation, followed by Curitiba, Guarapuava, União da Vitória, Irati, Laranjeiras do Sul, and Pato Branco nucleus. The Parana State is the fifth largest one in Eucalyptus planted area in Brazil, and Telemaco Borba, the regional nucleus of Ponta Grossa, is the county with the largest area planted with Eucalyptus in the State, with 45 thousand hectares.

KEYWORDS: Classification, Spatial area, Forest stands. 


\section{INTRODUÇÃO}

Atuando como um grande fornecedor de matériaprima aos diversos setores da indústria, a atividade florestal surge como uma estratégia para o desenvolvimento do Brasil, tornando-o altamente competitivo no mercado exterior, além de contribuir para as questões ambientais, como a proteção e recuperação de recursos hídricos e de solos, a minimização dos efeitos causados através das emissões dos gases de efeito estufa (GEE), bem como diminuindo a pressão pelo uso das florestas nativas.

O Brasil é um dos maiores praticantes da silvicultura, atingindo altos níveis de produtividade decorrentes das favoráveis condições de solo e clima, da disponibilidade de terra e do alto grau de conhecimento técnicocientífico. Estima-se que a área ocupada por florestas plantadas no Brasil seja de 7,74 milhões de hectares, o que corresponde a 0,9\% do território nacional (IBÁ, 2016). Segundo Andrade (2015), a projeção para até 2020, no Brasil, é de duplicação desta área ocupada por florestas plantadas, com projetos de investimentos de $\mathrm{R} \$$ 53 bilhões.

O setor brasileiro de florestas plantadas é responsável por $91 \%$ de toda a madeira produzida para fins industriais no país, e apenas $9 \%$ da madeira é originário de florestas nativas manejadas (IBÁ, 2016). O setor representa 5,5\% do PIB industrial nacional e $1,1 \%$ de toda a riqueza gerada no país, gerando mais de 660 mil empregos formais (EMBRAPA, 2015). No ano de 2015, as indústrias do setor de papel e celulose brasileiro viram suas exportações aumentarem em 6,1\%, totalizando U\$\$ 7,8 bilhões, ainda nesse mesmo ano, o setor de papel e celulose foi o de maior crescimento de valor de mercado na bolsa de valores, com expansão de $59,6 \%$ ou R\$ 26,6 bilhões (IBÁ, 2016).

Robustos investimentos com aumento da capacidade são prognosticados para o setor, pois este deve crescer em 6,5 milhões de toneladas ao ano a partir de 2018, até o ano de 2016 foram 17,2 milhões de toneladas (IBÁ, 2016). O Brasil se tornou o maior produtor mundial de celulose de Eucalyptus (fibra curta), em que esse gênero ocupa o primeiro lugar em termos de área plantada no país, com um total de 5,56 milhões de hectares (IBÁ, 2016).

Representando uma das principais atividades econômicas do estado do Paraná, a exploração madeireira era baseada no corte da Araucária e Imbuia, no entanto, a escassez destas espécies juntamente com a lei de incentivos fiscais (LEI no 5.106/66), impulsionaram o início dos plantios florestais, surgindo como opção econômica em regiões onde haviam condições adversas de relevo, clima ou solo. Atualmente, o Paraná é o maior detentor de plantios de pinus, com mais de 600.000 hectares, e o quinto em produção de eucalipto (IBÁ, 2016). O mercado paranaense é bastante consolidado e muito diversificado, segundo a SEAB (2013), o valor bruto da produção (VBP) do setor florestal, em 2013, foi de $\mathrm{R} \$ 3,96$ bilhões, o que representa $6,5 \%$ do desempenho da produção agrícola do estado.

Apesar de o setor de florestas plantadas ser fortemente consolidado no país, ainda existem poucos dados estatísticos oficiais e as informações sobre o setor florestal são bastante conflitantes, demonstrando apenas de maneira macro a localização e distribuição dos cultivos florestais, havendo carência de informações primárias advinda de levantamentos diretos. Faz-se necessário a obtenção de informações claras e precisas do setor florestal, em que os levantamentos sejam fundamentados em dados mais precisos para que as estatísticas do setor tenham maior credibilidade, pois estas servirão para direcionar metas de plantio, aumento de oferta, direcionamento de linhas de pesquisa, dentre outros.

Portanto, o mapeamento das florestas plantadas é um trabalho fundamental para nortear o planejamento estratégico, fornecer informações precisas para a iniciativa pública e privada, para a definição de políticas públicas voltadas ao setor e, até mesmo, servir de base técnica para atrair novos investidores para o setor florestal nacional.

Diante do exposto, objetivo desse trabalho foi mapear e quantificar o total de áreas de plantações florestais do gênero Eucalyptus no estado do Paraná para dar suporte ao planejamento socioeconômico do estado e do Brasil.

\section{MATERIAL E MÉTODOS}

\section{Área de estudo}

Para a realização deste estudo foi necessário o mapeamento de toda a extensão territorial do estado do Paraná, localizado na região Sul do Brasil, num total de 199.307,945 km² (IBGE, 2015), correspondente à de 2,35\% do território Brasileiro. Quanto à classificação climática do estado, os climas predominantes são Cfa (Clima temperado úmido com verão quente) e Cfb (clima temperado úmido com verão temperado), conforme a classificação de Köppen-Geiger (ITCG, 2008).

Para melhor descrição do estado, este estudo o classificou em seis regiões, onde cada região é composta 
por um ou mais Núcleos Regionais (NR), estes definidos pela Secretaria de estado da Agricultura e do Abastecimento (SEAB). As regiões são assim denominadas: Centro-Oeste, Centro-Sul, Litoral, Noroeste, Norte e Oeste. Segundo a SEAB (2013), considerando a taxa de participação da renda destas regiões que são oriundas de produtos agrícolas, em que a atividade florestal contribui com $1 \%$ do Valor Bruto de Produção para a região Centro-Oeste, 9\% para o Litoral, $1 \%$ para o Noroeste, $3 \%$ para o Norte, $1 \%$ para o Oeste e $14 \%$ para a região Centro-Sul.

\section{Metodologia}

O desenvolvimento da metodologia empregada no presente estudo, bem como a coleta, processamento e análise dos dados foram realizados em conjunto com a equipe da Unidade Regional Sul do Serviço Florestal Brasileiro (UR-Sul/SFB) e a Secretaria de estado da Agricultura e do Abastecimento (SEAB). A metodologia adotada contempla duas fases:

A primeira fase deste estudo contemplou o levantamento de informações das empresas florestais do estado associadas à Associação Paranaense de Empresas de Base Florestal (APRE), envolvendo o uso de questionários específicos. Durante a primeira fase houve primeiramente a identificação das empresas florestais do estado para então, realizar o contato inicial e envio dos questionários.

No questionário entregue às empresas buscou-se obter informações gerais dos plantios florestais, em que houve mobilização das empresas em ceder as informações referentes aos dados de cadastro (empresa, endereço, contato, localização geográfica, responsável pelas informações), ramo de atuação (papel e celulose, siderurgia, painéis, produtores independentes, outros), totais de áreas plantadas (própria, arrendada, fomentada, outros), áreas de preservação permanente (APP) e reserva legal $(R L)$, consumo de madeira por ano, entre outras, assim como informações geográficas sobre os plantios, como arquivos georreferenciados (em formato vetorial como shapefile, .dwg ou. $\mathrm{kml}$, ou ainda em forma de mapas georreferenciados e até mesmo não georreferenciados), além de informações sobre esses plantios (fazenda, número do talhão, área, ano de plantio, espécie, espaçamento, regime de manejo).

O questionário foi enviado para 52 empresas detentoras de plantios florestais no estado, sendo 41 empresas associadas à APRE e 11 não associadas, estas pertencentes ao núcleo regional de Guarapuava. O contato com as empresas não associadas à APRE foi possível devido ao apoio da Prefeitura Municipal de Guarapuava e da Cooperativa Florestal da região.

Das 52 empresas entrevistadas por meio do questionário, apenas 21 responderam ou retornaram as informações, dentro elas estão: Águia Florestal Indústria de Madeiras, Amata/Florespar Florestal, Ambiental Florestas, Amílcar de Rezende Dias - SEPAC, Arauco Forest Brasil S/A, Berneck S.A. Painéis e Serrados, Emilio B. Gomes e Filhos S/A, Empreendimentos Florestais Cambijú LTDA, F. Slaviero \& Filhos S.A. Comércio de Madeiras, Ibema, Iguaçu Celulose e Papel S/A, Indústria de Compensados Guararapes, Klabin S/A, Madem Florestamento LTDA, Plenovale, Pinho Past, Reinhofer, Remasa, Rigesa, Santa Maria e Vale do Corisco.

As empresas forneceram os dados com as áreas plantadas de diferentes espécies, assim como a base cadastral relacionada, em um total de mais de 400 mil hectares de plantios. Os dados fornecidos pelas empresas foram fundamentais para calibrar a acurácia na análise visual na classificação por gênero (Pinus e Eucalyptus) dos polígonos confeccionados pela equipe do projeto realizado na segunda fase, aumentando a confiabilidade dos resultados. Neste trabalho serão apresentados os resultados das plantações do gênero Eucalyptus.

A segunda fase, como complementação à primeira, envolveu a utilização de imagens de satélite para o levantamento nas áreas onde não houve retorno de questionário das empresas de modo a completar os resultados. Para a realização do mapeamento lançou-se mão da classificação visual de imagens de satélite de alta resolução para identificar as plantações de Eucalyptus no estado.

Foram utilizadas imagens dos satélites RapidEye referentes ao ano de 2011, as quais estavam disponíveis no período de início do trabalho, estas foram obtidas através do catálogo do Ministério do Meio Ambiente (MMA) e são consideradas imagens de domínio público. Composta por uma constelação de cinco satélites, lançados em 2008, a imagem RapidEye permite obter imagens em 5 bandas do espectro eletromagnético (azul, verde, vermelho, RedEdge e infravermelho próximo), com resolução espacial de 5 metros (PINAGÉ, 2013; ALMEIDA FILHO et al. 2013).

Após alguns testes, decidiu-se utilizar a composição de bandas RGB 5-4-2 (infravermelho próximo, RedEdge e verde), pois mostrou-se a mais adequada. De acordo com SCCON (2015), a banda RedEdge foi especificamente desenvolvida para diferenciação da vegetação, situada numa faixa do espectro eletromagnético que tem alta 
correlação com a fluorescência da clorofila. Para cobrir toda a área do estado foi necessário um conjunto de 393 imagens.

O banco de dados geográfico foi estruturado em um sistema de coordenada UTM, Fuso 22 Sul e Datum WGS 84 (World Geodetic System - 1984). Definiu-se a escala de mapeamento em 1:12.000 e considerando o tamanho do pixel $(5 \mathrm{~m})$, a menor unidade mapeável foi de $576 \mathrm{~m}^{2}$, correspondendo a aproximadamente 23 pixels. 0 mapeamento foi realizado através da vetorização dos polígonos com plantios de Eucalyptus, de forma manual, para isso, utilizou-se o software livre Quantum GIS (QGIS), empregando desde a versão 1.8 (Lisboa) até a 2.8 (Wien).

Utilizou-se também, para auxiliar na identificação dos talhões com o cultivo de Eucalyptus, base de dados como Google Maps e Bing Maps, disponíveis pelo plugin OpenLayers, assim como a base de dados disponibilizada pelas empresas florestais. De maneira auxiliar, ainda foram utilizadas imagens do satélite SPOT com data de 2005, do Google Earth e do Google Street View como apoio na etapa de classificação.

Considerando o banco de dados disponível e com o intuito de gerar resultados confiáveis, foram definidos dois critérios a serem utilizados na classificação, são eles: núcleo regional da $S E A B$ e o gênero da espécie plantada. $A$ primeira estratificação, de localização, foi obtida pelo cruzamento do shape de reflorestamento com as regionais da SEAB. Para o critério gênero, a classificação baseou-se nos padrões de cor e textura nas imagens. Pode-se dizer que é relativamente fácil diferenciar vegetação nativa e reflorestamentos porque a vegetação nativa é mais heterogênea e com textura mais rugosa do que uma área de silvicultura, que é mais homogênea ou uniforme (FLORENZANO, 2002).

Em se tratando de reflorestamento, concentram-se no estado do Paraná principalmente dois gêneros: Eucalyptus spp. e Pinus spp. Por pertencerem a grupos distintos de vegetação (folhosas e coníferas), possuem um comportamento espectral bastante distinto, facilitando, a sua identificação. A diferenciação das plantações de Eucalyptus em relação aos demais tipos de florestas plantadas deu-se principalmente pelo padrão de cor, textura, forma, contexto das imagens e análise da série histórica de imagens SPOT 2005. De forma geral, determinou-se que as áreas de Eucalyptus apresentaram predomínio de cor laranja-claro (plantios jovens) a laranja-escuro (plantios maduros), de forma regular e textura lisa.

Mesmo com o uso de imagens de alta resolução espacial, por se tratar de análise visual, os erros na identificação dos polígonos de florestas plantadas são plausíveis e podem ser confundidos com outras culturas.

Portanto, para verificar a acurácia do mapeamento foram selecionados, de maneira aleatória, 988 polígonos classificados como floresta, os quais foram checados em campo com apoio do Instituto de Florestas do Paraná e confrontados com os resultados gerados a partir do mapeamento. O mapa resultante foi comparado com a checagem de campo, resultando em uma matriz de confusão, ou matriz de erros, a partir da qual foi possível verificar a qualidade do mapeamento (PONZONI et al. 2012). Devido à defasagem temporal entre as imagens e a data de checagem (entre 2014-2015), consideraram-se como pontos válidos somente os polígonos que puderam ser verificados em campo como sendo plantios anteriores a 2011.

Outros pormenores metodológicos deste estudo constam do relatório técnico do levantamento, intitulado "Mapeamento dos plantios florestais do estado do Paraná" (EISFELD; NASCIMENTO, 2015).

\section{RESULTADOS E DISCUSSÃO}

Foi possível identificar, a partir dos dados obtidos de empresas florestais e com a classificação das cenas, que no estado do Paraná as florestas plantadas com espécies do gênero Eucalyptus somam 340.315 hectares, representando $34,2 \%$ da área total plantada no estado. A região com a maior concentração de florestas de Eucalyptus foi a Centro-Sul, que concentra aproximadamente $62 \%$ da área plantada (210.687 hectares). Para as demais regiões, o somatório de toda a área plantada com Eucalyptus foi de 60.385 ha no Norte, 30.170 ha no Oeste, 29.670 ha no Noroeste, 9.339 ha no Centro-Oeste, e apenas 65 ha no Litoral (Figura 1 e Tabela 1).

A partir da matriz de confusão calculou-se uma exatidão global de aproximadamente $96,6 \%$, este resultado mostra que o levantamento apresentou acurácia satisfatória, representando com fidedignidade a realidade da área plantada com Eucalyptus no estado. Segundo o IBÁ (2016), as plantações de Eucalyptus no estado somam 285.125 hectares, valor 16,22 \% inferior em relação ao apresentado no presente levantamento, que é de 340.315 hectares, já o IBGE (2014) estima que sejam 687.635 hectares de florestas plantadas com Eucalyptus, valor $102,1 \%$ superior à área mapeada neste trabalho. Esta diferença pode ser explicada pelas diferentes metodologias utilizadas nos levantamentos. 


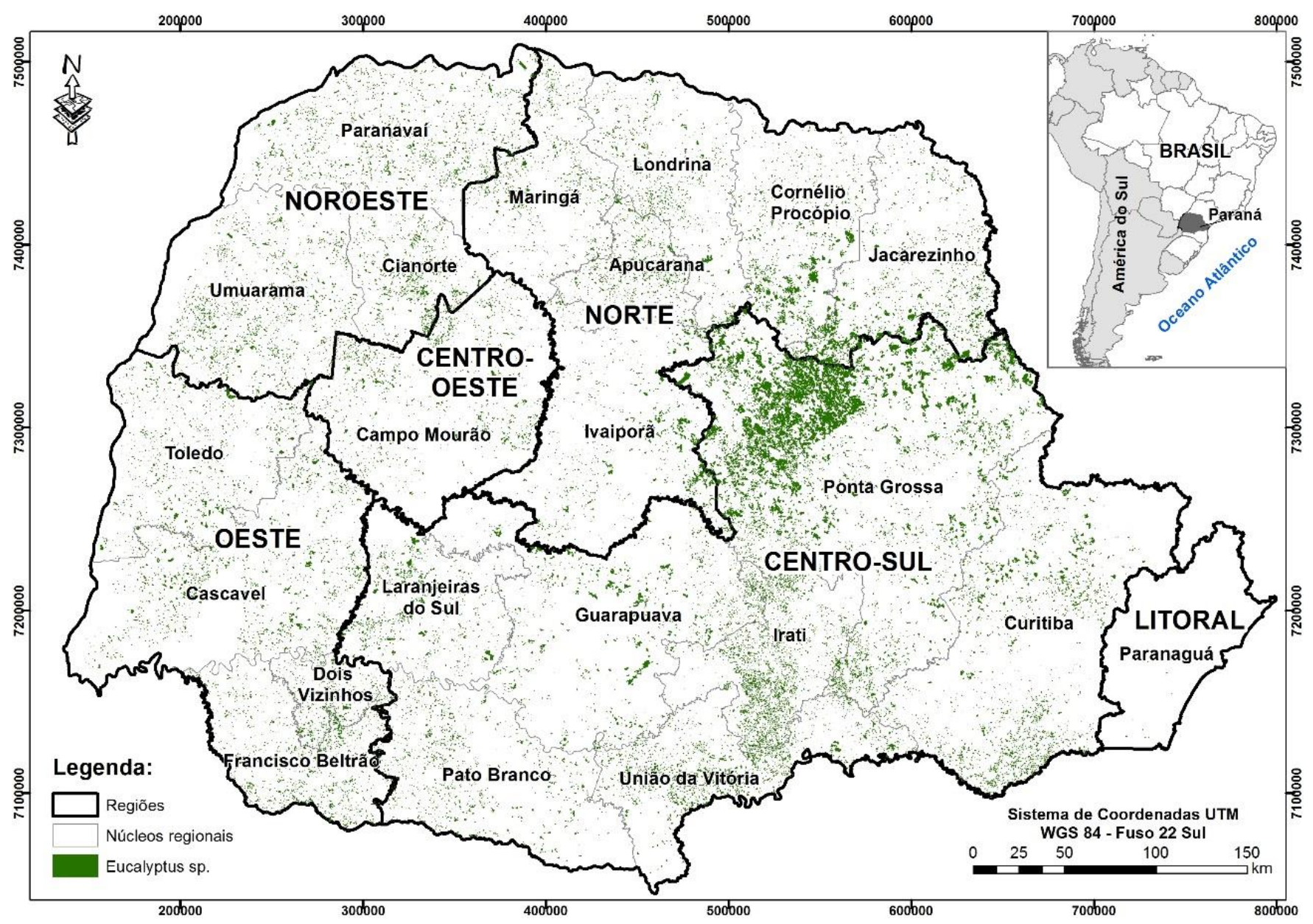

Figura 1. Localização das plantações florestais de Eucalyptus spp. no estado do Paraná.

No presente trabalho, as áreas plantadas com Eucalyptus foram contabilizadas a partir de questionários entregues às empresas e por meio de mapeamento. 0 mapeamento foi realizado a partir da classificação visual das imagens, com resolução de $5 \mathrm{~m}$, utilizando o software Quantum GIS, bandas espectrais RGB 5-4-2 e a acuracidade foi obtida através da matriz de confusão (96,6 \% de acuracidade). Já os resultados obtidos pelo IBÁ se tratam de estimativas a partir de questionários respondidos pelas empresas associadas à IBÁ, pela APRE, pela AFUBRA e pelo contato direto com empresas da cadeia produtiva de árvores plantadas não associadas à IBÁ.

No relatório apresentado pela IBÁ admite-se margem de erro de $15 \%$. O IBGE, por sua vez, gerou a estimativa por meio da coleta de informações realizada mediante aplicação de questionário para cada município do país, a estimativa do IBGE incluiu as áreas de corte-raso, em que a madeira foi recém-colhida e, portanto, não permitiu a identificação acurada na imagem de satélite, por isso houve grande diferença entre os resultados obtidos neste trabalho e os obtidos pelo IBGE.

Da área total levantada com povoamentos florestais de Eucalyptus, 243.188 hectares foram classificados com base nas imagens RapidEye, e 97.127 ha foram identificados a partir da base de dados repassada pelas empresas florestais. Foram mapeados 87.623 polígonos de Eucalyptus, a distribuição deste montante, por classe de área, está apresentada na Tabela 2. Nota-se que, do total de polígonos mapeados, $81,08 \%$ estão concentrados em plantios de até 5 hectares, obtendo também o maior valor em área, com $91.123,5$ ha mapeados $(26,78 \%$ do total).

\section{Região Centro-Sul}

A região Centro-Sul possui uma área de 8.397.223 ha e é composta por 102 municípios, estes são divididos em sete núcleos regionais, sendo eles: Curitiba, Guarapuava, Irati, Laranjeiras do Sul, Pato Branco, Ponta Grossa e União da Vitória. Nesta região concentra-se a maior área de Eucalyptus do estado, possui cerca de 210.687 ha de plantio (61,91\% do total). Considerando a área total de seu território, o percentual de plantações de Eucalyptus no mesmo é de $2,51 \%$. 
Tabela 1. Quantificação de áreas das plantações florestais de Eucalyptus spp. no estado do Paraná por região e núcleo

\begin{tabular}{|c|c|c|c|c|}
\hline Região & Núcleo & $\begin{array}{l}\text { Área } \\
\text { (ha) }\end{array}$ & $\begin{array}{c}\% \\
\text { Núcleo }\end{array}$ & $\begin{array}{c}\text { \% Área } \\
\text { Total }\end{array}$ \\
\hline \multirow{8}{*}{ Centro-Sul } & Curitiba & 16.597 & 7,88 & 4,88 \\
\hline & Guarapuava & 14.037 & 6,66 & 4,12 \\
\hline & Irati & 9.925 & 4,71 & 2,92 \\
\hline & $\begin{array}{l}\text { Laranjeiras do } \\
\text { Sul }\end{array}$ & 8.229 & 3,91 & 2,42 \\
\hline & Pato Branco & 6.913 & 3,28 & 2,03 \\
\hline & Ponta Grossa & 143.849 & 68,28 & 42,27 \\
\hline & União da Vitória & 11.137 & 5,29 & 3,27 \\
\hline & Subtotal & 210.687 & 100,00 & 61,91 \\
\hline \multirow{7}{*}{ Norte } & Apucarana & 4.912 & 8,13 & 1,44 \\
\hline & $\begin{array}{l}\text { Cornélio } \\
\text { Procópio }\end{array}$ & 13.880 & 22,99 & 4,08 \\
\hline & Ivaiporã & 9.849 & 16,31 & 2,89 \\
\hline & Jacarezinho & 19.714 & 32,65 & 5,79 \\
\hline & Londrina & 6.062 & 10,04 & 1,78 \\
\hline & Maringá & 5.968 & 9,88 & 1,75 \\
\hline & Subtotal & 60.385 & 100,00 & 17,74 \\
\hline \multirow{5}{*}{ Oeste } & Cascavel & 12.199 & 40,43 & 3,58 \\
\hline & Dois Vizinhos & 2.683 & 8,89 & 0,79 \\
\hline & $\begin{array}{c}\text { Francisco } \\
\text { Beltrão }\end{array}$ & 6.698 & 22,20 & 1,97 \\
\hline & Toledo & 8.591 & 28,48 & 2,52 \\
\hline & Subtotal & 30.170 & 100,00 & 8,87 \\
\hline \multirow{4}{*}{ Noroeste } & Cianorte & 6.310 & 21,27 & 1,85 \\
\hline & Paranavaí & 13.690 & 46,14 & 4,02 \\
\hline & Umuarama & 9.670 & 32,59 & 2,84 \\
\hline & Subtotal & 29.670 & 100,00 & 8,72 \\
\hline \multirow{2}{*}{$\begin{array}{l}\text { Centro- } \\
\text { Oeste }\end{array}$} & Campo Mourão & 9.339 & 100,00 & 2,74 \\
\hline & Subtotal & 9.339 & 100,00 & 2,74 \\
\hline \multirow{2}{*}{ Litoral } & Paranaguá & 65 & 100,00 & 0,02 \\
\hline & Subtotal & 65 & 100,00 & 0,02 \\
\hline Total Geral & & 340.315 & & 100,00 \\
\hline
\end{tabular}

O núcleo regional de Ponta Grossa possui 143.849 ha de plantações de Eucalyptus, isto representa $42,27 \%$ de toda a área plantada com este gênero do estado. Neste núcleo encontram-se os cinco municípios com maiores áreas de Eucalyptus de todo o Paraná: Telêmaco Borba, Ortigueira, Reserva, Tibagi e Arapoti. A alta concentração de plantios de Eucalyptus no núcleo de Ponta Grossa é justificado pelo grande número de empresas florestais presentes neste núcleo, principalmente indústrias de papel e celulose e indústria de painéis de madeira. A sua localização no eixo estratégico entre a capital e o interior, confere à região um potencial de crescimento expressivo.
Tabela 2. Quantidade de polígonos por classe de área de Eucalyptus spp.

\begin{tabular}{cccccc}
\hline \multicolumn{2}{c}{ Limite (ha) } & \multirow{2}{*}{ Área (ha) } & $\%$ & \multirow{2}{*}{ No polígonos } & $\%$ \\
\cline { 1 - 5 } Inferior & Superior & & & & \\
\hline- & $<5$ & $91.123,50$ & 26,78 & 71.044 & 81,08 \\
5,1 & 10 & $58.297,66$ & 17,13 & 8.267 & 9,43 \\
10,1 & 20 & $70.764,49$ & 20,79 & 5.076 & 5,79 \\
20,1 & 30 & $40.384,02$ & 11,87 & 1.666 & 1,90 \\
30,1 & 40 & $25.781,69$ & 7,58 & 755 & 0,86 \\
40,1 & 50 & $15.323,93$ & 4,50 & 345 & 0,39 \\
50,1 & 100 & $26.108,63$ & 7,67 & 396 & 0,45 \\
100,1 & 200 & $7.409,36$ & 2,18 & 57 & 0,07 \\
$>200$ & & $5.122,12$ & 1,51 & 17 & 0,02 \\
\hline \multicolumn{2}{c}{ Total } & $\mathbf{3 4 0 . 3 1 5}$ & $\mathbf{1 0 0 , 0 0}$ & $\mathbf{8 7 . 6 2 3}$ & $\mathbf{1 0 0 , 0 0}$ \\
\hline \multicolumn{7}{c}{} & & & &
\end{tabular}

Segundo a SEAB (2014), também se destaca nesta região a produção de toras para serraria e laminadora e a produção de mudas florestais. Ainda segundo a SEAB (2014), nesta região se aponta uma trajetória de aumento para a produção de Eucalyptus e redução do Pinus, e dentro desse processo de substituição, as toras para laminação tendem a diminuir. O núcleo regional de Ponta Grossa se caracteriza pela maior proporção das áreas (cerca de 34,2\%) ocupadas por matas e florestas (IPARDES, 2004).

Ainda segundo IPARDES (2004), essa ocupação devese aos ciclos de madeira e as indústrias de papel e papelão que se instalaram nessa região, assim como às dificuldades de expansão das lavouras no local, visto que existem restrições naturais de fertilidade, profundidade dos solos e relevo ondulado. Mesmo diante das restrições, a região apresenta-se com uma diversificada base produtiva rural, com expressivo rebanho bovino e plantel de aves, com grandes extensões de produção de grãos, como a soja, o milho, o trigo e o feijão, também é destaque na produção de batata e na produção de fumo (IPARDES, 2013). Destaca-se também neste núcleo a consolidada estrutura agroindustrial, com grau de diversificação no beneficiamento de grãos, lácteos e carnes (IPARDES, 2013).

O núcleo regional de Curitiba, compõe a área mais urbanizada do estado, possui 16.849 ha de plantações de Eucalyptus, representando cerca de $4,88 \%$ de toda a área plantada com Eucalyptus do estado. Destaca-se no núcleo de Curitiba a produção de toras para serraria e laminadora, papel e celulose e também a renda pela lenha (utilizada em cadeias produtivas, por exemplo, na agricultura e pecuária em processos de secagem de grãos e aquecimento de aviários) (SEAB, 2014).

Esse núcleo contempla os municípios do Vale do Ribeira, sendo eles: Adrianópolis, Bocaiúva do Sul, Cerro 
Azul, Doutor Ulysses, Itaperuçu, Rio Branco do Sul e Tunas do Paraná, esses municípios destacam-se por ter a produção florestal como uma de suas principais atividades econômica, pois devido ao relevo bastante acidentado, dificulta a agricultura, então os plantios florestais surgiram como uma opção econômica aos proprietários rurais (IPARDES, 2004).

Os núcleos regionais de Ponta Grossa e Curitiba correspondem, conjuntamente, a 47,15\% de toda a área plantada com Eucalyptus no estado do Paraná, sendo estratégicas para o planejamento do setor florestal e para as políticas e programas voltados ao desenvolvimento socioeconômico dos seus municípios.

No núcleo de Guarapuava foram identificados 14.037 ha de plantações de Eucalyptus, representando $4,12 \%$ de toda a área plantada com esse gênero no estado. Os municípios de maior destaque são Guarapuava, Prudentópolis e Pinhão, que possuem grande tradição florestal, responsáveis por ceder dados de 8.994 ha (cerca de $64 \%$ do total de área de eucalipto do núcleo) para este levantamento.

O núcleo de Guarapuava abrange empresas florestais de destaque para a indústria de painéis, indústria de serrados e indústria de celulose. Por sua localização central no estado, os plantios deste núcleo também são destinados ao abastecimento de indústrias localizadas em outras regiões. O núcleo de Guarapuava tem destaque na produção de pinhão (SEAB, 2012), no entanto, a principal atividade econômica é a agricultura, como plantios de soja, batata, feijão e fumo (IPARDES, 2004). Com relação à erva-mate, este núcleo é o maior produtor do estado e a mais expressiva no âmbito nacional (IPARDES, 2013).

O núcleo regional de União da Vitória possui uma área com Eucalyptus de 11.137 ha, o que representa 3,27\% da superfície plantada com esse gênero no estado. Esse núcleo é bastante importante em termos de áreas plantadas com Eucalyptus, principalmente nos municípios de Bituruna, União da Vitória e São Mateus do Sul, detentores da maior área plantada do núcleo. Destaca-se neste núcleo a indústria de painéis, embalagens, moveleira e serrada. Este núcleo tem uma economia bastante diversificada, e a produção florestal se encontra entre as grandes contratadoras de mão de obra, em que os municípios deste núcleo têm encontrado nessa atividade uma possibilidade de desenvolvimento econômico e geração de empregos (IPARDES, 2010).

O núcleo de União da Vitória também se destaca pela concentração de Florestas de Araucária, com grandes extensões localizadas em propriedades particulares, destaca-se também a exploração combinada de erva- mate e de pastagens. Em relação à indústria de alimentos, o processamento da erva-mate continua a ocupar posição de destaque neste núcleo e, com as cooperativas, ampliam-se as atividades de agroindustrialização (arroz, mandioca, trigo, milho e leite), ao lado destes, o fumo persiste como atividade de forte concentração regional (IPARDES, 2004).

O núcleo regional de Irati também é bastante destacado ao que se refere às plantações de Eucalyptus, ocupando a quinta posição em termos de área plantada com esse gênero dentro da região Centro-Sul. A área plantada com esse gênero se aproxima dos $10 \mathrm{mil}$ hectares, representando cerca de $3 \%$ de toda a área com Eucalyptus no Paraná.

No núcleo de Irati, inserem-se os municípios de Mallet, Irati e Rio Azul, com as maiores áreas mapeadas das plantações de Eucalyptus identificadas nesse núcleo. Nesse núcleo encontra-se a Floresta Nacional de Irati, criada após a escassez da oferta da madeira de araucária, com a finalidade de iniciar o plantio de espécies exóticas para abastecer as indústrias da região, neste núcleo que se iniciou o plantio de pinus no estado do Paraná. Atualmente o núcleo contém um pólo diversificado de industrialização e beneficiamento de madeira. Apesar de ser tradicionalmente florestal, neste núcleo também há destaque na produção de feijão e grande concentração de produção de tabaco (IPARDES, 2004, 2013).

O núcleo regional de Laranjeiras do Sul apresentou 8.229 ha de plantios com Eucalyptus, representando $2,42 \%$ de todo o plantio desse gênero no estado do Paraná. A maior parte desses plantios está concentrada nos municípios de Guaraniaçu, com 2.058,3 ha, Quedas do Iguaçu, com 1.468,7 ha e Diamante do Sul, com $1.417,4$ ha plantados. Esse núcleo também tem destaque na produção de soja, além da produção de carne e leite (SEAB, 2015).

O núcleo regional de Pato Branco apresentou a menor proporção em termos de área plantada com Eucalyptus na região, com 6.913 ha, o que representa cerca de $2 \%$ do total plantado com esse gênero no estado. Os municípios com maior destaque quanto à área plantada com Eucalyptus são: Coronel Domingos Soares, com 1.185,5 ha, Clevelândia, com 976,5 ha e Coronel Vivida, com 959 ha plantados. Os plantios a Oeste deste núcleo são caracterizados por pequenos povoamentos de Eucalyptus destinados, principalmente, para energia. Outros destaques deste núcleo estão voltados à agroindústria como a produção de soja, frango e silagem (IPARDES, 2004; SEAB, 2015). 


\section{Região Norte}

A região Norte tem área total de 4.377.320 ha, sendo composta por 129 municípios, divididos em 6 núcleos regionais, são eles: Apucarana, Cornélio Procópio, Ivaiporã, Jacarezinho, Londrina e Maringá. A região apresenta a segunda maior área plantada com o gênero Eucalyptus no estado, com 60.385 ha, representando $17,74 \%$ da área total plantada com Eucalyptus no Paraná. Esse valor representa cerca de $1,4 \%$ da superfície total dessa região. Essa região destaca-se o desempenho de algumas commodities e matérias-primas industriais, como a cana, soja e milho, bem como o incremento na produção de alguns hortifrutigranjeiros, além de ser a principal produtora de café no estado (IPARDES, 2004).

Os núcleos em que a produção de Eucalyptus é mais pronunciada são os de Jacarezinho e Cornélio Procópio, juntos somam 33.594 ha de plantios, cerca de $56 \%$ de toda a produção da região. No núcleo de Jacarezinho três municípios se destacam na produção de florestas de Eucalyptus, são eles: Curiúva, com 6.266,5 ha, São José da Boa Vista, com $2.405,8$ ha e Figueira, com $1.838,7$ ha. Esse núcleo apresentou 19.714 ha de plantios com Eucalyptus, representando 5,79\% de todo o plantio desse gênero no estado do Paraná. Os plantios de Eucalyptus localizados nesse núcleo são, em geral, destinados para produção de energia e ao abastecimento de grandes empresas florestais. Além da produção florestal, esse núcleo é caracterizado por conter grandes extensões de cultivo de cana-de-açúcar e de café (IPARDES, 2013).

A área de plantio com o gênero Eucalyptus no núcleo de Cornélio Procópio totalizou 13.880 ha, 4,08\% de todo o plantio desse gênero no estado, com destaque para os municípios de São Jerônimo da Serra, com 4.366,4 ha, Congonhinhas, com 2.878,9 ha e Sapopema, com 2.085,9 ha. Assim como no núcleo de Jacarezinho, os plantios de Eucalyptus localizados neste núcleo são, em geral, destinados para produção de energia e ao abastecimento de grandes empresas florestais. Se destacam neste núcleo os cultivos de soja e milho, além de outras culturas de produção familiar, como o feijão, mandioca e café (IPARDES, 2013).

O núcleo regional de Ivaiporã possui 9.849 ha de plantações com o gênero Eucalyptus, 2,89\% de toda a área plantada com este gênero no estado do Paraná. Destacam-se na produção de Eucalyptus os municípios de Cândido de Abreu, com 3.869 ha, Rio Branco do Ivaí, com $1.399,1$ ha e Faxinal, com 1.016,3 ha. Os plantios a norte deste núcleo são destinados principalmente para produção de energia e os plantios ao sul são destinados ao abastecimento de empresas florestais. Este núcleo regional destaca-se o desempenho de plantios de canade-açúcar, soja e milho (IPARDES, 2004), sendo a soja o principal produto (SEAB, 2015).

O núcleo regional de Londrina possui 6.062 ha de plantios de Eucalyptus, $1,78 \%$ de toda a área plantada com este gênero no estado do Paraná. Os municípios que se destacam na produção de Eucalyptus são: Londrina, com 1.571,7 ha, Tamarana, com 705,5 ha e Jaguapitã, com 705,1 ha. Tais plantios são caracterizados por pequenos povoamentos plantados com eucalipto destinados, principalmente, para energia. Este núcleo tem maior vocação agrícola e pecuária, caracterizada pela agricultura intensiva de lavouras de grãos e plantios de café (IPARDES, 2013). Os produtos principais produzidos neste núcleo regional são a soja, milho, cana-de-açúcar e o frango (SEAB, 2015).

A área de plantio com o gênero Eucalyptus no núcleo de Maringá é de 5.968 ha, representando 1,75\% de toda área plantada com este gênero no estado. As cidades que se destacam em termos de área plantada com o gênero Eucalyptus são: Nova Esperança, com 798,7 ha, Astorga, com 484,9 ha e Atalaia, com 469,4 ha. Assim como no núcleo regional de Londrina, esses plantios são caracterizados por pequenos povoamentos destinados, principalmente, para energia. A maior vocação do núcleo regional de Maringá se dá à atividade agrícola e pecuária, os produtos principais são a soja, o milho, a cana-deaçúcar e o frango (SEAB, 2015).

O núcleo regional de Apucarana apresenta a menor área plantada com o gênero Eucalyptus da região norte, com 4.912 ha, 1,44\% de toda a superfície plantada com este gênero em todo o estado do Paraná. Os maiores plantios estão localizados nos municípios de Apucarana, com 1.054,6 ha, Arapongas, com 755,1 ha e Mauá da Serra, com 639 ha. O principal produto da maioria dos municípios desse núcleo é a produção de frango (SEAB, 2015).

\section{Região Oeste}

A região Oeste tem uma área total de 2.907 .751 ha, composta por 75 municípios, divididos em 4 núcleos regionais, são eles: Cascavel, Toledo, Francisco Beltrão e Dois Vizinhos. A região apresenta a terceira maior área plantada com o gênero Eucalyptus no estado, com 30.170 ha, representando $8,87 \%$ da área total plantada com Eucalyptus no estado do Paraná. Esse valor representa $1,04 \%$ da superfície total dessa região. Essa região destaca-se pela moderna base produtiva agropecuária, 
com alto desenvolvimento produtivo, comandada pelo desenvolvimento do agronegócio cooperativado (IPARDES, 2004). Outro destaque da região é a pecuária, com a criação de aves e suínos (IPARDES, 2010).

A área de plantio com o gênero Eucalyptus no núcleo de Cascavel é de 12.199 ha, representando 3,58\% de toda área plantada com este gênero no estado. As cidades com a maior área plantada com o gênero Eucalyptus são: Cascavel, com 2.684,2 ha, Três Barras do Paraná, com 822,3 ha e Céu Azul, com 752,3 ha. Os plantios deste núcleo são compostos por pequenos povoamentos plantados com destinação, principalmente, para energia. Neste núcleo se destaca a produção agrícola e pecuária como soja, frango, leite e mandioca (SEAB, 2015). Também de destaca neste núcleo a produção de trigo e a produção animal (IPARDES, 2013).

O núcleo regional de Toledo possui 8.591 ha de plantações com o gênero Eucalyptus, o que significa $2,52 \%$ de toda a área plantada com este gênero no estado do Paraná. Destaca-se na produção de florestas de eucaliptos as cidades de Toledo, com 1.546,8 ha, Ouro Verde do Oeste, com 1.052,7 ha e Terra Roxa, com 961,4 ha. Os plantios deste núcleo são compostos por pequenos povoamentos plantados com destinação, principalmente, para energia. O núcleo de Toledo tem sua produção econômica voltada à produção de soja, frango e criação de suínos (IPARDES, 2010; SEAB, 2015).

No núcleo regional de Francisco Beltrão foram mapeados 6.698 hectares com plantações de Eucalyptus, representando $1,97 \%$ de toda a área plantada com este gênero no estado. As maiores áreas plantadas de Eucalyptus nesse núcleo regional foram verificadas nos municípios de Enéas Marques, com 987,1 ha, Marmeleiro, com 724 ha e Francisco Beltrão, com 689,4 ha. Os plantios localizados neste núcleo são destinados tanto para a produção de energia quanto para o abastecimento de empresas florestais. O núcleo de Francisco Beltrão se destaca pela produção agrícola e pecuária como soja, frango, leite e mandioca (SEAB, 2015).

O núcleo regional de Dois Vizinhos possui a menor área mapeada com plantios de Eucalyptus da região Oeste, totalizando 2.683 ha, representando $0,79 \%$ de toda a área plantada com este gênero no estado do Paraná. As maiores plantações com o gênero Eucalyptus neste núcleo são verificadas nos municípios de Dois Vizinhos, com 650,3 ha, Nova Esperança do Sudoeste, com 621,7 ha e Salto do Contra, com 464,9 ha. Este núcleo apresenta poucas e pequenas áreas plantadas com Eucalyptus, pois sua produção econômica é voltada à carne de frango (SEAB, 2015).

\section{Região Noroeste}

A região Noroeste possui área de 2.508 .567 ha, composta por 72 municípios, estes divididos em três núcleos regionais: Paranavaí, Umuarama e Cianorte. Nesta região se concentram 29.670 ha com plantios de Eucalyptus, representando $8,72 \%$ do total plantado no estado do Paraná. Considerando a área total de seu território, o percentual de plantações de Eucalyptus no mesmo é de $1,18 \%$. As atividades agropecuárias mantêm participação expressiva na ocupação da mão-de-obra regional, estruturadas principalmente em torno da pecuária bovina, no entanto, possui culturas consideráveis de soja, milho, cana-de-açúcar, mandioca e aves, além da produção de casulos do bicho-da-seda, café e fruticultura (IPARDES, 2004, 2010, 2013).

O núcleo regional de Paranavaí possui 13.690 ha de florestas de Eucalyptus, isso representa 4,02\% de todo o plantio com este gênero do estado do Paraná. As cidades que se destacam na produção de Eucalyptus dentro deste núcleo regional são: Paranavaí, com 2.075,2 ha, Querência do Norte, com 1.102,7 ha e Planaltina do Paraná, com 786,5 ha. Os plantios de Eucalyptus neste núcleo são caracterizados por pequenos povoamentos destinados, principalmente para a produção de energia. No entanto, as principais atividades econômicas desenvolvidas nesse núcleo regional provêm das atividades agropecuárias, como a cana-de-açúcar, a soja, arroz, carnes bovina e de frango, além da produção de ovos (SEAB, 2015). Também é destaque na região o plantio de mandioca (IPARDES, 2013).

No núcleo regional de Umuarama foram mapeados 9.670 ha de plantações com o gênero Eucalyptus, o que significa $2,84 \%$ de toda a área plantada com este gênero em todo o estado do Paraná. As cidades que se destacam na produção de florestas com Eucalyptus nesse núcleo são: Iporã, com 1.317,1 ha, Umuarama, com 1.192 ha e Altonia, com $1.102,5$ ha. Os plantios de Eucalyptus nesse núcleo são caracterizados por pequenos povoamentos destinados, principalmente para a produção de energia. A atividade agropecuária é destaque no núcleo, como os plantios de cana-de-açúcar, soja, arroz, a produção de carnes bovina e de frango, e a produção de ovos (SEAB, 2015).

O núcleo regional de Cianorte possui 6.310 ha mapeados com Eucalyptus, correspondendo a 1,85\% de toda a área plantada com este gênero no estado do Paraná. Os municípios que se destacam na produção de Eucalyptus são: Cianorte com 2.547,3 ha, Tapejara com 843,4 ha e Terra Boa com 589 ha. Os plantios localizados 
nessa região são caracterizados por pequenos povoamentos destinados, principalmente para energia. No núcleo de Cianorte, as principais atividades agropecuárias são a cana-de-açúcar e o frango (SEAB, 2015).

\section{Região Centro-Oeste}

A região Centro-Oeste compreende uma área de 1.160.998 ha, composta por 24 municípios e corresponde ao núcleo regional de Campo Mourão. Nesta região concentram-se 9.339 ha com plantios de Eucalyptus, representando $2,74 \%$ do total plantado no estado do Paraná. Considerando a área total de seu território, o percentual de plantações de Eucalyptus no mesmo é de $0,8 \%$. Os municípios com as maiores áreas de Eucalyptus são: Campo Mourão com 1.613 hectares, Araruna com 1.045,8 ha e Luiziana com 934 ha. O núcleo regional de Campo Mourão não é destacado pela sua atividade florestal, pois se trata de uma região tradicionalmente agrícola, em que se destacam os segmentos da produção de açúcar e álcool, óleo, gorduras vegetais, algodão e mandioca (IPARDES, 2004).

\section{Região Litoral}

A região Litoral compreende uma área de 633.762 ha, composta por 6 municípios e corresponde ao núcleo regional de Paranaguá. Nesta região concentram-se 65 ha com plantios de Eucalyptus, a região com a menor área plantada com o gênero do estado do Paraná, representando apenas $0,02 \%$ do total plantado no estado. Guaratuba foi o município que apresentou a maior área com Eucalyptus, com 41,3 ha, já o município de Pontal do Paraná apresentou menos de um hectare, não foram mapeados plantios com Eucalyptus nas cidades de Antonina e Matinhos. Essa região não tem foco maior na produção florestal, tradicionalmente a região é caracterizada através da atividade pesqueira, atividades extrativistas e o turismo ecológico (IPARDES, 2013).

Os últimos levantamentos acerca das áreas florestais com Eucalyptus no estado do Paraná têm sido realizados de forma indireta, muitas das vezes por meio de questionários aplicados junto a EMATER, IBGE, prefeituras, cooperativas e outras entidades ligadas à agricultura e através de declarações de empresas às entidades de classe e às empresas de consultoria. Esses levantamentos são geralmente incompletos, os quais reportam, em sua maioria, as áreas das empresas florestais e não a totalidade dos plantios, o qual deve incluir pequenos produtores rurais. Portanto, há carência de estatísticas completas e oficiais desse importante recurso econômico, fundamental para o desenvolvimento socioeconômico do estado.

O último inventário florestal realizado no estado ocorreu em 1980, conduzido pelo IBDF (Instituto Brasileiro de Desenvolvimento Florestal). Consequentemente, estatísticas oficiais estão bastante defasadas. Este trabalho é de grande importância para atualizar o quadro das áreas florestais com Eucalyptus no estado, fornecendo informações precisas para o poder público e iniciativa privada e, até mesmo, servindo de base técnica para atrair novos investimentos.

Segundo a Indústria Brasileira de Árvores, entidade de classe mais representativa do setor florestal brasileiro, o estado do Paraná possui uma área de 285.125 ha de florestas de Eucalyptus, sendo o estado com a sexta maior área plantada com esse gênero no Brasil (IBÁ, 2016). Os resultados no presente trabalho denotam uma área 340.315 ha de plantios de Eucalyptus no estado, ou seja, cerca de 19\% maior. Essa diferença é explicável devido ao fato de que a informação do IBÁ corresponde a levantamentos indiretos. Contudo, essa soma difere da área informada pelo IBGE (2014) em seu estudo sobre a produção da extração vegetal e da silvicultura do estado, que informa 687.635 ha de plantios de Eucalyptus no estado do Paraná.

O setor florestal paranaense é bastante consolidado, no entanto, apesar dessa pujança, existem lacunas de informações para uma melhor organização desse setor, parte das quais é preenchida com este trabalho. $O$ conhecimento da área plantada por região é fundamental para direcionar linhas de financiamento, metas de plantio, aumento da oferta, pesquisas, áreas prioritárias de fomento florestal, estabelecimento de políticas e programas governamentais e para o planejamento dos investimentos setoriais.

O presente trabalho é uma primeira abordagem das áreas de plantios florestais com Eucalyptus do estado do Paraná, no entanto, estas informações devem ser sempre atualizadas, e para isso é necessário que a base de dados que compõe esse mapeamento seja constantemente alimentada, ainda faz-se necessário avançar mais, no sentido de se obter refinamentos quanti-qualitativos, particularmente sobre a distribuição etária dos povoamentos, aspectos sanitários, estoques volumétricos e sortimentos de madeira, entre outros.

Nota-se neste trabalho que há uma grande concentração de maciços florestais com Eucalyptus na região Centro-Sul, com destaque para os núcleos 
regionais de Ponta Grossa e Curitiba, a região Norte também possui uma área expressiva de povoamentos com Eucalyptus, com destaque para os núcleos regionais de Jacarezinho e Cornélio Procópio. Na Tabela 3 é possível observar que os 25 municípios com as maiores áreas de plantio de Eucalyptus do estado do Paraná juntos, concentram mais da metade da área total plantada com Eucalyptus no estado.

Tabela 3. Municípios com maior área plantada com povoamentos de Eucalyptus spp. no estado do Paraná

\begin{tabular}{|c|c|c|c|}
\hline Ordem & Município & Área (ha) & $\%$ total \\
\hline 1 & Telêmaco Borba & $45.347,00$ & 13,33 \\
\hline 2 & Ortigueira & $19.574,60$ & 5,75 \\
\hline 3 & Reserva & $14.206,20$ & 4,17 \\
\hline 4 & Tibagi & $13.779,60$ & 4,05 \\
\hline 5 & Arapoti & $10.617,50$ & 3,12 \\
\hline 6 & Sengés & $7.498,40$ & 2,20 \\
\hline 7 & Imbaú & $6.938,20$ & 2,04 \\
\hline 8 & Curiúva & $6.266,50$ & 1,84 \\
\hline 9 & Jaguariaíva & $5.894,60$ & 1,73 \\
\hline 10 & Guarapuava & $5.395,40$ & 1,59 \\
\hline 11 & São Jerônimo da Serra & $4.366,40$ & 1,28 \\
\hline 12 & Cândido de Abreu & $3.869,00$ & 1,14 \\
\hline 13 & Ventania & $3.636,30$ & 1,07 \\
\hline 14 & Castro & $3.487,70$ & 1,02 \\
\hline 15 & Ipiranga & $2.949,00$ & 0,87 \\
\hline 16 & Congonhinhas & $2.878,90$ & 0,85 \\
\hline 17 & Cascavel & $2.684,20$ & 0,79 \\
\hline 18 & Cianorte & $2.547,30$ & 0,75 \\
\hline 19 & São José da Boa Vista & $2.405,80$ & 0,71 \\
\hline 20 & Rio Branco do Sul & $2.171,40$ & 0,64 \\
\hline 21 & Piraí do Sul & $2.153,70$ & 0,63 \\
\hline 22 & Mallet & $2.153,40$ & 0,63 \\
\hline 23 & Bituruna & $2.150,80$ & 0,63 \\
\hline 24 & Sapopema & $2.085,90$ & 0,61 \\
\hline 25 & Paranavaí & $2.075,20$ & 0,61 \\
\hline \multicolumn{2}{|r|}{ Subtotal } & $177.133,00$ & 52,05 \\
\hline \multicolumn{2}{|r|}{ Total } & 340.315 & 100,00 \\
\hline
\end{tabular}

Telêmaco Borba é o município com a maior cobertura de plantações de Eucalyptus, com mais de 45 mil hectares. Os sete municípios com maior área plantada (mais de 117 mil hectares) estão todos no núcleo de Ponta Grossa. A maior parte desses maciços está comprometida com o grande número de empresas florestais regionais, principalmente de papel e celulose e indústria de painéis de madeira.

\section{CONCLUSÕES}

O Paraná é o sexto estado com a maior área plantada com o gênero Eucalyptus no Brasil, cujos povoamentos cobrem uma superfície equivalente a $1,71 \%$ do estado. A região Centro-Sul representa cerca de 61,91\% da área plantada, sendo os núcleos de Ponta Grossa e Curitiba os de maior expressão, com mais de $52 \%$ da área florestal de Eucalyptus no estado.

A área plantada com Eucalyptus está concentrada em 25 municípios, que representam mais da metade da superfície total com esse gênero no Paraná. O município de Telêmaco Borba, núcleo regional de Ponta Grossa, é o município com a maior área plantada com Eucalyptus no estado, com cerca de 45 mil hectares.

A metodologia empregada neste estudo, que envolve aplicação de questionários, mapeamento visual com o emprego de imagens de satélite e levantamentos em campo, é adequada para mapear florestas plantadas do gênero Eucalyptus.

\section{REFERÊNCIAS}

ALMEIDA FILHO, N. O. Mapeamento da cobertura da terra no município de Alfenas-MG utilizando imagens do satélite RapidEye. In: Simpósio Brasileiro de Sensoriamento Remoto SBSR, 16., 2013, Foz do Iguaçu. Anais... São José dos Campos: INPE, 2013. p. 1502-1508.

ANDRADE, W. O Brasil vai dobrar sua produção de madeira plantada. E o mundo também. 2016. Disponível em: <http://iba.org/pt/convidados/o-brasil-vai-dobrar-sua-producao -de-madeira-plantada-e-o-mundo-tambem>. Acesso em: 04/07/2016.

EMBRAPA - Empresa Brasileira de Pesquisa Agropecuária. Plantações florestais: Geração de benefícios com baixo impacto ambiental. 2015. Disponível em: <http://www.arc.org.br/ download/biblioteca/licenciamento \%20iba I2015 15 12.pdf>. Acesso em: 05/07/2016.

EISFELD, R. L.; NASCIMENTO, F. A. F. Mapeamento dos plantios florestais do estado do Paraná. Curitiba: Instituto de Florestas do Paraná, 2015. 72 p.

FLORENZANO T. G. Imagens de Satélite para estudos ambientais. São Paulo: Universidade de São Paulo, 2002. 97 p.

IBÁ - Indústria Brasileira de Árvores. Anuário Estatístico IBÁ 2016. Brasília, 2016. 96 p.

IBGE - Instituto Brasileiro de Geografia e Estatística. Brasil, Censo 2015. Disponível em: <http://www.ibge.gov.br/ estadosat/perfil.php?sigla=pr> Acesso em: 08/07/2016.

IBGE - Instituto Brasileiro de Geografia e Estatística. Brasil, Floresta Plantada 2014. 2014. Disponível em: <http://www.florestal.gov.br/snif/recursos-florestais/as-floresta 
s-plantadas. Acesso em: 09/07/2016.

IPARDES - Instituto Paranaense de Desenvolvimento Econômico e Social. Indicadores de desenvolvimento sustentável por bacias hidrográficas do estado do Paraná. Curitiba, PR: IPARDES, 2013. 245 p.

IPARDES - Instituto Paranaense de Desenvolvimento Econômico e Social. Nota Técnica - Características do emprego no setor agropecuário e florestal no Paraná. Curitiba: IPARDES, 2010. 31 p.

IPARDES - Instituto Paranaense de Desenvolvimento Econômico e Social. Leituras regionais - mesorregiões geográficas paranaenses. Curitiba: IPARDES, 2004. 32 p.

ITCG - Instituto de Terras, Cartografia e Geociências. Clima estado do Paraná. Disponível em: <http://www.itcg.pr.gov.br>. Acesso em: 09/07/2015.

PINAGÉ, E. R. Estudos dos impactos da exploração madeireira em áreas de concessão florestal utilizando imagens orbitais. 2013. 103 f. Dissertação (Mestrado em Ciências Florestais). Universidade de Brasília, Brasília.

PONZONI, F. J.; SHIMABUKURO, Y. E.; KUPLICH, T. M. Sensoriamento Remoto da Vegetação. 2. ed. São Paulo: Universidade de São Paulo, 2012. 164 p.

SCCON. Imagens RapidEye. 2015. Disponível em: <http://www.sccon.com.br/rapideye.html>. Acesso em: $10 / 07 / 2016$.

SEAB - Departamento de Economia Rural. Produtos Florestais Análise da Conjuntura Agropecuária. 2012. Disponível em: <http://www.agricultura.pr.gov.br/arquivos/File/deral/Prognost icos/corte 2012 13.pdf>. Acesso em: 12/07/2016.

SEAB - Departamento de Economia Rural. Valor bruto da produção: ano base 2013. 2013. Disponível em: <http://www.agricultura.pr.gov.br/modules/conteudo/conteud o.php?conteudo=156>. Acesso em: 11/07/2016.

SEAB - Departamento de Economia Rural. Produção agrícola paranaense por município. 2014. Disponível em: <http://www.agricultura.pr.gov.br/modules/conteudo/conteud o.php?conteudo=137>. Acesso em: 07/07/2016.

SEAB - Departamento de Economia Rural. Produtos florestais. 2015. Disponível em: <http://www.agricultura.pr.gov.br/arqui vos/File/deral/Prognosticos/produtos florestais 2013 14.pdf>. Acesso em 11/07/2016. 